\section{A New Technology That Determines Low-oxygen Thresholds in Controlled- atmosphere-stored Apples}

\author{
John M. DeLong, ${ }^{1}$ \\ Robert K. Prange, ${ }^{1}$ \\ Jerry C. Leyte, ${ }^{2}$ \\ Peter A. Harrison ${ }^{3}$
}

\begin{abstract}
Additional INDEX WORDs. Malus $\times$ domestica Borkh., chlorophyll fluorescence, controlled atmosphere storage, dynamic low-oxygen controlled atmosphere storage, fluorescence interactive response monitor, fruit quality, HarvestWatch, postharvest
\end{abstract}

Summary. HarvestWatch is a new chlorophyll fluorescence (F)-based technology that identifies the lowoxygen threshold for apple (Malus $x$ domestica) fruit in dynamic low- $\mathrm{O}_{2}$ controlled atmosphere (DLOCA) storage environments [e.g., $<1 \%$ oxygen $\left(\mathrm{O}_{2}\right)$ ]. Immediately following harvest, 'Cortland', 'Delicious', 'Golden Delicious', 'Honeycrisp', 'Jonagold' and 'McIntosh' fruit were cooled and loaded into $0.34 \mathrm{~m}^{3}\left(12.0 \mathrm{ft}^{3}\right)$ storage cabinets. A static controlled atmosphere (CA) regime of $1.5 \% \mathrm{O}_{2}, 1.5 \%$ carbon dioxide $\left(\mathrm{CO}_{2}\right)$ and $3{ }^{\circ} \mathrm{C}(37.4$ $\left.{ }^{\circ} \mathrm{F}\right)\left[0^{\circ} \mathrm{C}\left(32.0^{\circ} \mathrm{F}\right)\right.$ for 'Delicious' and 'Golden Delicious'] was established for the control fruit, while the low- $\mathrm{O}_{2}$ threshold was identified by a spike in the fluorescence parameter, $\mathrm{F} \alpha$, as the $\mathrm{O}$, levels in the DLOCA cabinets were lowered below 1\%. The DLOCA storages were then maintained at $\mathrm{O}$, levels of $0.1 \%$ to $0.2 \%$ above the threshold value for each cultivar, which returned $\mathrm{F} \alpha$ to prethreshold signatures. Quality

Atlantic Food and Horticulture Research Centre contribution no. 2268. The authors thank D.M. Hodges and Bill Ricketts for reviewing this manuscript.

${ }^{1}$ Research scientist, Atlantic Food and Horticulture Research Centre, Agriculture and Agri-Food Canada, 32 Main St., Kentville, NS, Canada, B4N 1J5; Corresponding author; email DeLongJ@ agr.gc.ca.

${ }^{2}$ Agricultural engineer, Satlantic Inc., Richmond Terminal-Pier 9, 3481 North Marginal Rd., Halifax, NS, Canada, B3K 5 X8.

${ }^{3}$ Research technician. measurements following 5 to 9 months of storage and a 7-day shelf life of 20 ${ }^{\circ} \mathrm{C}\left(68.0^{\circ} \mathrm{F}\right)$, showed that the HarvestWatch fruit were generally firmer, had no incidence of superficial scald in 'Cortland' and 'Delicious' apples, and did not accumulate fermentative volatile compounds. The HarvestWatch system permits rapid, real-time measurements of the status of stored apple fruit in ultra low- $\mathrm{O}_{2}$ environments without the inconvenience of breaking the room's atmosphere. Our results indicate that HarvestWatch facilitates what may be the highest possible level of fruit quality retention in long-term, low- $\mathrm{O}_{2}$ apple storage without the use of scald-controlling or other chemicals before storage.

$\longrightarrow$ hlorophyll fluorescence has been evaluated with varying degrees of success as an indicator or predictor of storage quality for fruits and vegetables (DeEll et al., 1995, 1996).

The main limitations for $\mathrm{F}$ usage in postharvest applications reside in the small fruit surface area covered per measurement, the difficulty of relating a fluorescence signal to a specific disorder(s) or quality state of the produce, and the inability of a single fluorescence model to be an accurate predictor for a number of cultivars of a given species. In addition, the necessity of removing the fruit or vegetable sample out of a sealed storage atmosphere to measure $\mathrm{F}$ has limited its industrial adoption. Hence, real time measurements of the produce in an undisturbed storage atmosphere have not been possible or have been difficult to obtain.

The recent development of a F-based technology to determine the low- $\mathrm{O}_{2}$ threshold is, therefore, an important development in real-time sensing methods for chlorophyllcontaining plant products (Prange et al., 2002, 2003). The HarvestWatch system (Satlantic Inc., Halifax, N.S., Canada) is a rapid, nondestructive technology which allows the operator to monitor the condition of stored fruit without the inconvenience of breaking the room's atmosphere. As low- $\mathrm{O}_{2}$ tolerances for fruit can vary from year to year, the HarvestWatch method facilitates a dynamic approach for establishing the lowest tolerable $\mathrm{O}_{2}$ regime in a storage environment. Identification of the low-O threshold is based solely on an immediate response of the fruit to far-red illumination and not on historical data that may have little bearing on the present condition of the stored crop.

Hence, this study was undertaken to evaluate the influence of DLOCA storage on apple fruit quality in several cultivars, including two that are susceptible to superficial scald, following establishment of the low- $\mathrm{O}_{2}$ threshold by the HarvestWatch fluorescence system.

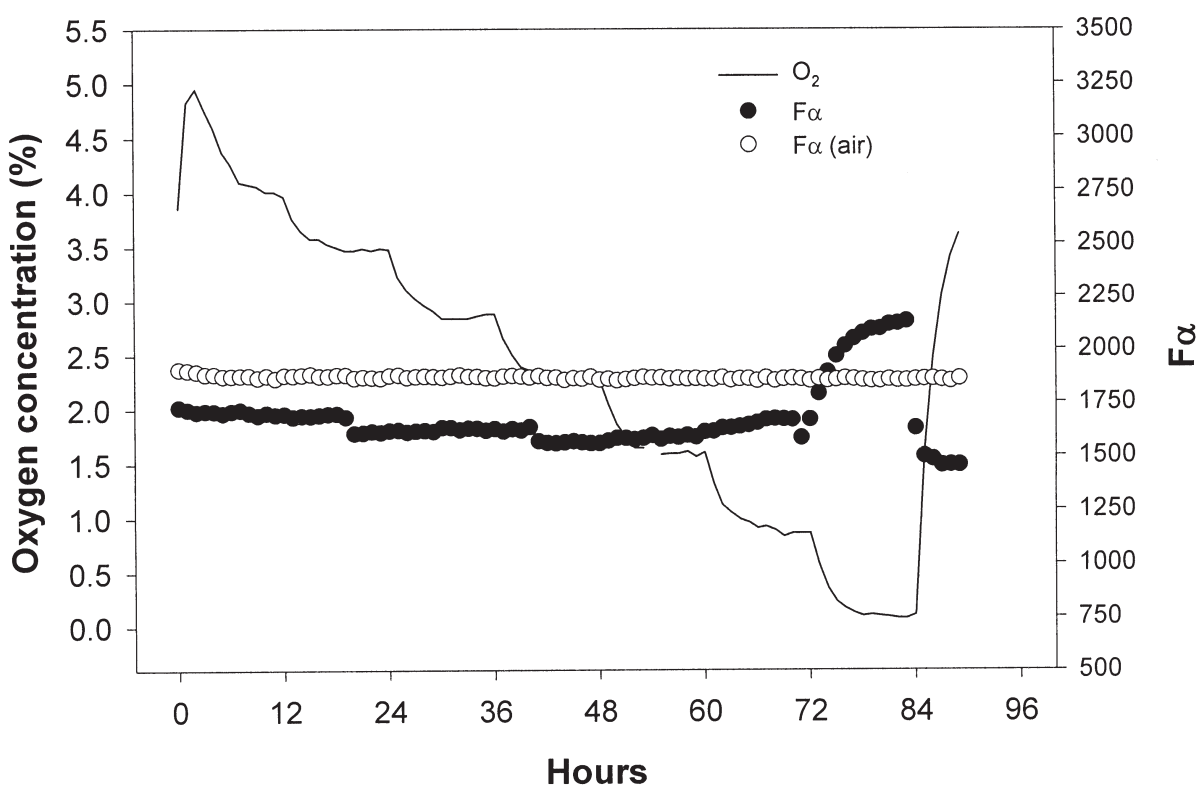

Fig. 1. An example of the $\mathrm{F} \alpha$ fluorescence signal detected in 'Summerland McIntosh' fruit held at $20^{\circ} \mathrm{C}\left(68.0^{\circ} \mathrm{F}\right)$ in air (open circle) and in a progressively diminished oxygen environment (dark circle). The spike in $\mathrm{F} \alpha$ begins as the chamber oxygen levels fall below $1 \%$ at $72 \mathrm{~h}$ and continues upward until the oxygen concentration is increased at $84 \mathrm{~h}$ (Prange et al., 2003). 
Table 1. Low-oxygen $\left(\mathrm{O}_{2}\right)$ thresholds determined for each apple cultivar by HarvestWatch and the subsequent range of oxygen levels employed in storage.

\begin{tabular}{lcc}
\hline Cultivar & $\begin{array}{c}\text { DLOCA } \\
\text { Low-O } \\
\text { threshold } \\
\text { (\%) }\end{array}$ & $\begin{array}{c}\text { Detting } \\
\text { for each } \\
\text { cultivar } \\
\text { (\%) }\end{array}$ \\
\hline Cortland & 0.5 & $0.6-0.8^{y}$ \\
Delicious & 0.4 & $0.5-0.8$ \\
Golden Delicious & 0.5 & $0.5-0.8$ \\
Honeycrisp & 0.4 & $0.5-0.8$ \\
Jonagold & 0.5 & $0.5-0.8$ \\
McIntosh & 0.8 & $0.9-1.0$ \\
\hline
\end{tabular}

${ }^{2}$ DLOCA $=$ dynamic low-oxygen controlled atmosphere.

yLOCA settings were maintained at $0.1 \%$ to $0.2 \%$ above the detected low-oxygen thresholds. The DLOCA oxygen ranges reflect the system variation encountered during the storage period.

\section{Materials and methods}

PLANT MATERIAL AND STORAGE CONDITIONS. 'Cortland', spur-type 'Delicious', 'Golden Delicious', 'Honeycrisp', 'Jonagold' and 'McIntosh' apples were harvested from commercial orchards or collected from packing houses immediately following harvest in the Annapolis Valley of Nova Scotia. Trees ranged in age from 5 to 15 years old and were on 'Malling 26' (M.26) or 'MallingMerton 111' (M.M.111) rootstocks. Following $24 \mathrm{~h}$ of harvest or sample collection, all fruit were cooled and stored at $3{ }^{\circ} \mathrm{C}\left(37^{\circ} \mathrm{F}\right)\left[0{ }^{\circ} \mathrm{C}\left(32^{\circ} \mathrm{F}\right)\right.$ for 'Delicious' and 'Golden Delicious'] in top-loading $0.34 \mathrm{~m}^{3}$ cabinets which were flushed with nitrogen gas until $\mathrm{O}_{2}$ levels of $1.5 \%$ (2\% for 'Cortland') were obtained (static, control CA). Following 5 to $7 \mathrm{~d}$ at $1.5 \%$, other cabinets were continuously flushed with nitrogen gas until the low- $\mathrm{O}_{2}$ threshold $(<1 \%)$ was identified by the spike in the fluorescence parameter, $\mathrm{F} \alpha$ (Fig. 1). The $\mathrm{O}_{2}$ level was then increased by $0.1 \%$ to $0.2 \%$ above the threshold level (DLOCA) for the duration of the storage period (Table 1). In both CA regimes, the $\mathrm{CO}_{2}$ level was maintained at $1.5 \%$ unless otherwise noted.

HaRvestwatch fluorescence sysTEM. HarvestWatch is a nondestructive fluorescence measurement system in which fluorescence interactive response monitor (FIRM) sensors (Fig. 2) detect apple fluorescence generated as a result of low-level LED-based farred irradiance emitted by each FIRM unit at a fixed geometry from the fruit.
HarvestWatch then uses the detected fluorescence signal to generate an estimate of Fo (DeEll et al., 1999) at zero irradiance, which is termed $\mathrm{F} \alpha$. In order to measure a relatively large sample surface area, the FIRM LEDs illuminate the fruit at a $10 \mathrm{~cm}(3.94$ inches) distance above the sample with a photon flux density ranging from 0.01 to $10 \mu \mathrm{mol} \cdot \mathrm{m}^{-2} \cdot \mathrm{s}^{-1}$, depending on the LED duty cycle. During each LED scan sequence, the fruit are probed by an increasing frequency of far-red light pulses over a short time duration. Typically, the sample is illumined by 10,000 LED flashes over a 180-s period once per hour, after which the average $F \alpha$ value for each scan period is calculated.

Under DLOCA conditions (e.g., $<1 \%$ ), a spike in F $\alpha$ occurs at the low$\mathrm{O}_{2}$ threshold, which demarcates the transition of the fruit from aerobic to anaerobic metabolism (Fig. 1). By maintaining a storage-room $\mathrm{O}_{2}$ concentration $0.1 \%$ to $0.2 \%$ above the low- $\mathrm{O}_{2}$ threshold, fruit can be held at the lowest possible $\mathrm{O}_{2}$ level resulting in high product quality without incurring anaerobic damage.

Fruit measurements. Fruit removed from the CA and DLOCA environments after 5 to 9 months of storage were held at $20^{\circ} \mathrm{C}$ for $7 \mathrm{~d}$. Cortical firmness $(\mathrm{N})$ was then measured on individual apples in a 10-apple sample with the fruit quality testor (Geo-Met Instrument, New Minas, N.S., Canada), having the time limit window set at $>0.1 \mathrm{~s}$ and $<1.0 \mathrm{~s}$ (DeLong et al., 2000). Superficial scald incidence was then visually assessed on 'Cortland' and 'Delicious' fruit and calculated as a percentage of the total sample showing the disorder.

Three volatile compounds associated with anaerobic metabolism-acetaldehyde, ethanol and ethyl acetate-were measured on a gas chromatograph (GC) following the 5, 7, and 9-month removals. Two fruit per treatment were quartered after the 7-d shelf life, with 1 quarter per fruit being sealed for $4 \mathrm{~h}$ of headspace equilibration in a $1-\mathrm{L}(0.26$-gal $)$ mason jar fitted with a septum lid. A 1-mL headspace sample was then extracted with a syringe and analyzed on a GC (Varian Inc., Walnut Creek, Calif.) with a SupelcoWax 10 column $(30 \mathrm{~m} \times 0.53$ mmi.d., 1.0-um coating thickness; $\mathrm{Su}$ pelco Inc., Bellefonte, Pa.), using ultrahigh purity helium (99.99\%; Praxair, Mississauga, Ont., Canada) as a carrier gas at a flow rate of $9 \mathrm{~mL} \cdot \mathrm{min}^{-1}$. The volatiles were detected by flame ionization using helium as the makeup gas at a flow rate of $30 \mathrm{~mL} \cdot \mathrm{min}^{-1}$; air and hydrogen flow rates were $30 \mathrm{~mL} \cdot \mathrm{min}^{-1}$ and $300 \mathrm{~mL} \cdot \mathrm{min}^{-1}$, respectively. The analysis was performed isothermally at $80{ }^{\circ} \mathrm{C}\left(176.0^{\circ} \mathrm{F}\right)$ with the injection port and detector temperatures set at $200^{\circ} \mathrm{C}\left(392.0^{\circ} \mathrm{F}\right)$. Volatile standards were generated by evaporating a known amount of authentic acetaldehyde, ethanol, and ethyl acetate from a piece of filter paper dropped into a 3.8 -L (1-gal) glass jar fitted with a Mininert gas-tight sampling valve (Alltech Assoc., Deer-

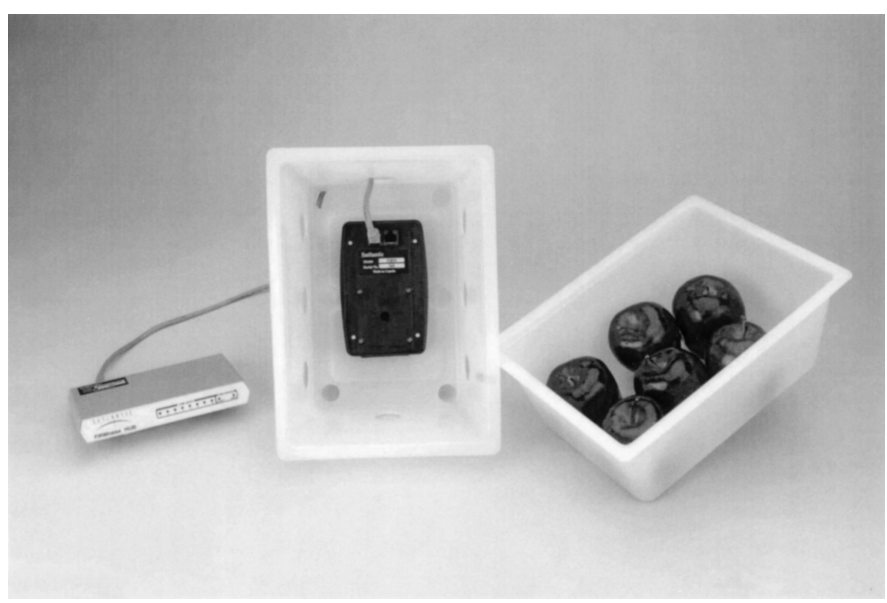

Fig. 2. The HarvestWatch fluorescence system showing the fluorescence interactive response monitor (FIRM) unit affixed in an upper sampling kennel (middle), apples in the bottom kennel (right) and a central hub (left). Before storage, apples are placed in the bottom kennel over which the upper kennel housing the FIRM unit is securely fastened. In storage, the FIRM units are wired to the hub which controls the interaction of electronic signals from a central computer to each attached FIRM device. 
Table 2. Apple firmness ( $1.0 \mathrm{~N}=\mathbf{0 . 2 2 5} \mathrm{lbf})$ after long-term controlled atmosphere (CA) or dynamic low-oxygen controlled atmosphere (DLOCA) storage, plus a 7 -d shelf life at $20^{\circ} \mathrm{C}\left(68.0{ }^{\circ} \mathrm{F}\right)$.

\begin{tabular}{|c|c|c|c|c|c|c|c|c|c|c|}
\hline \multirow{2}{*}{$\begin{array}{l}\text { Storage } \\
\text { (months) }\end{array}$} & \multicolumn{2}{|c|}{ Delicious } & \multicolumn{2}{|c|}{ Golden Delicious } & \multicolumn{2}{|c|}{ Honeycrisp } & \multicolumn{2}{|c|}{ Jonagold } & \multicolumn{2}{|c|}{ McIntosh } \\
\hline & CA & DLOCA & CA & DLOCA & $\mathrm{CA}$ & DLOCA & $\mathrm{CA}$ & DLOCA & CA & DLOCA \\
\hline 6 & 68.4 & 68.9 & 54.2 & $67.8^{* *}$ & 62.9 & 64.9 & 65.1 & $69.0^{* *}$ & 44.0 & $57.3^{* \star}$ \\
\hline 8 & 67.9 & $71.7^{* *}$ & 54.6 & $66.0^{* *}$ & --- & --- & 61.0 & $67.3^{* *}$ & 49.7 & $55.2^{* *}$ \\
\hline 9 & 65.2 & 68.5 & 57.2 & $62.1^{*}$ & --- & --- & 60.1 & $72.2^{* *}$ & --- & --- \\
\hline
\end{tabular}

"** Significant comparison of CA and DLOCA means $(\mathrm{n}=10)$ for each cultivar at each month at $0.05<P \leq 0.10$ or $P \leq 0.05$, respectively.

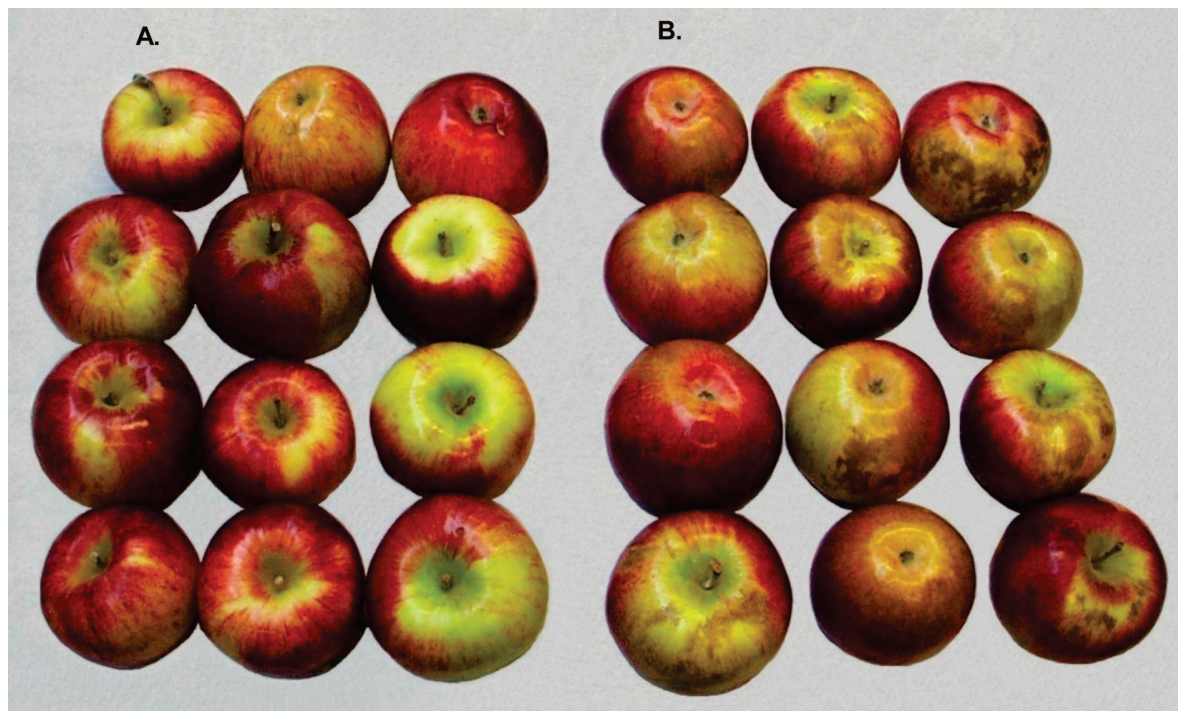

Fig. 3. Superficial scald expression in 'Cortland' fruit held for 6 months, in (A) a dynamic low oxygen controlled atmosphere (DLOCA) regime of $0.6 \%$ to $0.8 \%$ oxygen $\left(\mathrm{O}_{2}\right)$ and $2 \%$ carbon dioxide $\left(\mathrm{CO}_{2}\right)$, with the low- $\mathrm{O}_{2}$ threshold being first detected by Harvest-Watch; or (B) a static controlled atmosphere (CA) regime of $2 \% \mathrm{O}_{2}$ and $2 \% \mathrm{CO}_{2}$. Following storage removal, fruit were held for $7 \mathrm{~d}$ at $20^{\circ} \mathrm{C}$ $\left(68.0^{\circ} \mathrm{F}\right)$ before scald evaluation.

field, Ill.). Quantitation was done by comparison of the GC response of the sample to that of the standard volatile compounds (Song et al., 2001).

Statistical analysis. Analysis of variance was performed with PROC GLM, while treatment means were separated with PROC GLM's least significant difference (LSD) option (SAS Institute, 1994).

\section{Results and discussion}

Although fruit were removed from storage and measured monthly, only data from the 5-month removal and onwards will be discussed as the benefits of DLOCA storage became apparent during this period. Comparison of firmness means show that the DLOCA apples were generally firmer and when statistically significant, the firmness benefit in the DLOCA compared with the CA-stored fruit ranged from 3.8 to $13.6 \mathrm{~N}(0.854$ to 3.057 lbf) (Table 2). It is likely that the
DLOCA firmness benefits reported here would have been greater if the static CA environment was maintained at $\mathrm{O}_{2}$ levels of $2 \%$ to $3 \%$, which is a common $\mathrm{O}_{2}$ concentration range for many CA-stored apple cultivars.

The $1.5 \% \mathrm{O}_{2}$ concentration in the static CA regime was chosen to represent an aggressive low $\mathrm{O}_{2}$ setting that some commercial storage operators may choose as a low $\mathrm{O}_{2}$ limit. However, maintaining a storage room $\mathrm{O}_{2}$ level at $1.5 \%$ has been considered risky particularly for low- $\mathrm{O}_{2}$ sensitive cultivars like 'McIntosh'. The current regional recommendation for these cultivars in static, standard CA storage is $2.5 \% \mathrm{O}_{2}$, with $1.5 \% \mathrm{O}$, being considered the lowest safe limit (DeEll and Prange, 1994). The HarvestWatch system demonstrates that, by identifying the low- $\mathrm{O}_{2}$ threshold, apples can be beneficially held at $\mathrm{O}_{2}$ levels (e.g., <1\%) previously considered too low for long-term CA storage.

Superficial scald on susceptible cultivars causes significant economic loss annually as scalded fruit are not sold for fresh consumption. As superficial scald is an oxidation-related disorder, low $\mathrm{O}_{2}$ regimes can suppress its incidence (Lau et al., 1998; Little et al., 1982). The problem, however, is knowing the precise low $\mathrm{O}_{2}$ setting that provides scald control without inducing low- $\mathrm{O}_{2}$ damage to the fruit. The HarvestWatch system potentially eliminates this risk by identifying the low- $\mathrm{O}_{2}$ threshold, which may vary somewhat from year to year. Once identified, the storage operator can then set the $\mathrm{O}_{2}$ atmosphere at $0.1 \%$ to $0.2 \%$ above the threshold to avoid inducing fermentation. In the present study, superficial scald incidence ranged from $47 \%$ to $100 \%$ in static CA-stored fruit, while it was eliminated in DLOCA 'Delicious' (data not shown) and 'Cortland' (Fig. $3 \mathrm{~A}-\mathrm{B}$ ) without inducing anoxic damage by storing apples just above the low-O threshold (Fig. 1). It is possible that the HarvestWatch system may replace prestorage chemical dips like diphenylamine, which currently is a standard industrial practice for scald control.

The generation of acetaldehyde, ethanol and ethyl acetate can increase in apple fruit undergoing anaerobic fermentation (Changwen and Tiovonen, 2000; Gunes et al., 2001). Hence, these three volatiles were measured as indicators of cellular anoxia in the DLOCA environments established in this study. The data show that the fruit in DLOCA storage generated similar or lesser amounts of anaerobic compounds compared with CA-stored apples, indicating no evidence of fermentative metabolism (Figs. 4A-E). The increase in anaerobic volatiles in DLOCA-stored 'Delicious' at 5 and 9 months (Fig. $4 \mathrm{~A}$ ) and 'Jonagold' at 9 months (Fig. 4C) was not significant. In addition, no off-flavors were noted in the fruit from either the static CA or DLOCA environments (data not shown). 

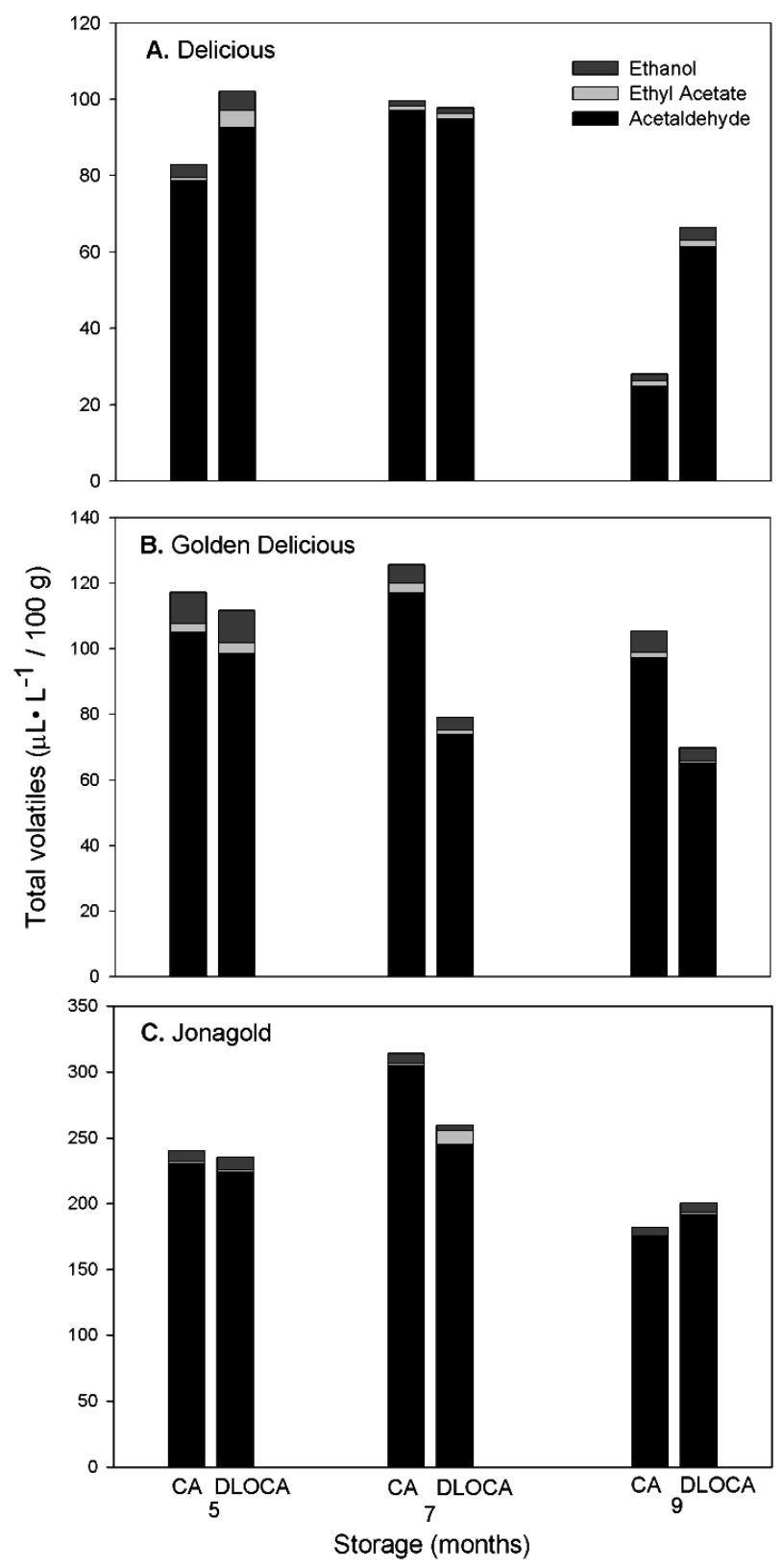

Fig. 4. Total headspace volatiles [acetaldehyde+ethanol+ethyl acetate in $\mu \mathrm{L} \cdot \mathrm{L}^{-1}(\mathrm{ppm})$ per $100 \mathrm{~g}(3.53$ oz) fruit] from (A) 'Delicious'; (B) 'Golden Delicious'; (C) 'Jonagold'; (D) 'Honeycrisp'; and (E) 'McIntosh'apples stored in static controlled atmosphere (CA) and dynamic low-oxygen controlled atmosphere (DLOCA) storage following 5 to 9 months of storage. Volatiles were measured following $7 \mathrm{~d}$ at $20{ }^{\circ} \mathrm{C}$ $\left(68.0^{\circ} \mathrm{F}\right){ }^{*}$ Significant at $P \leq 0.05$ for comparison of two storage treatments following a removal period.

Prange etal. (2003) observed that 'Summerland McIntosh' apples stored at $1.5 \% \mathrm{O}_{2}$ generated higher levels of acetaldehyde, ethanol and ethyl ac-

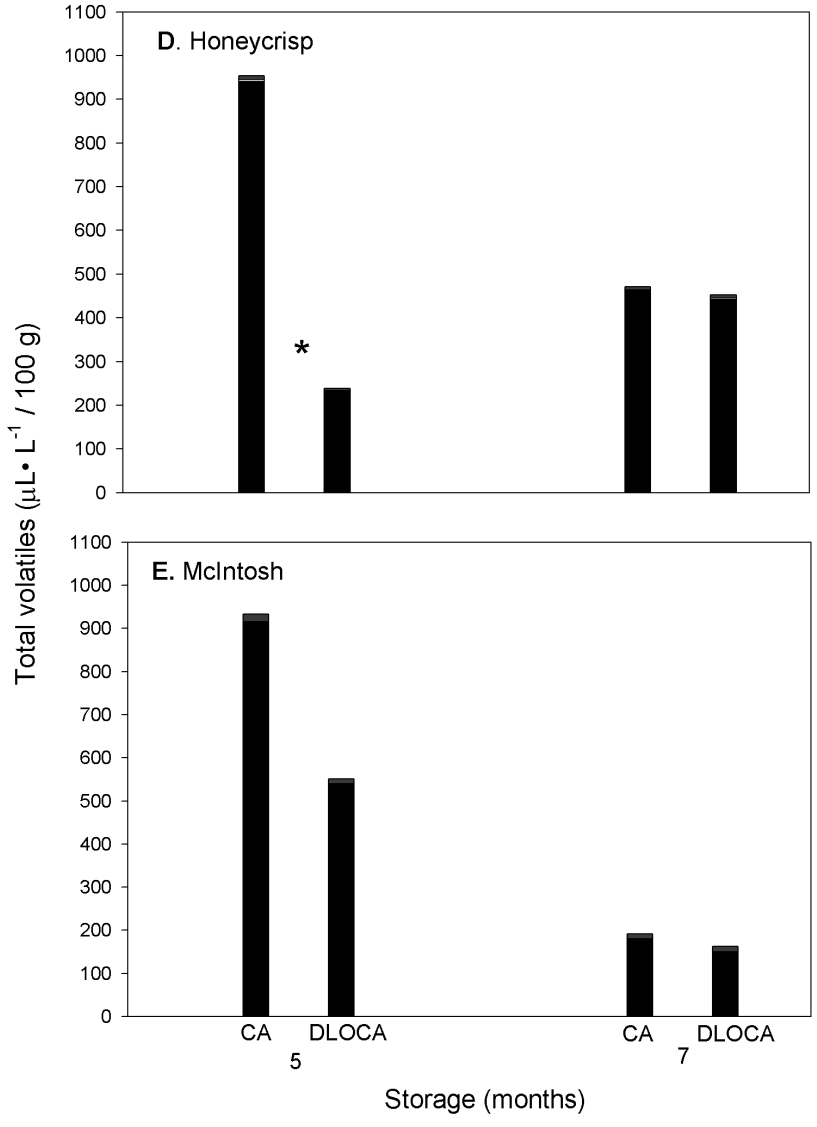

etate compared with fruit held in a low- $\mathrm{O}_{2}$ atmosphere of $0.9 \%$. The increase in acetaldehyde measured in DLOCA, compared with CA-stored 'Delicious' at 5 and 9 months in this present study, is likely not attributable to fermentation as the ethanol levels generated were relatively low (Fig. 4A). Although acetaldehyde, ethanol and ethyl acetate are indicative of anoxia in low $\mathrm{O}_{2}$ environments, the levels of these volatiles produced from apples held in refrigerated air storages $\left(21 \% \mathrm{O}_{2}\right)$ can be 2- to 15-fold higher than fruit held in low- $\mathrm{O}_{2}$, high- $\mathrm{CO}_{2}$ environments due to more advanced senescence (DeLong et al., unpublished data). It is likely that the fruit stored in the static CA regime of $1.5 \% \mathrm{O}_{2}$ were simply more highly senesced than those held in the DLOCA environment and as a result evolved higher levels of volatile compounds in general.

In conclusion, the HarvestWatch system is a new, real time, F-based technology that identifies the low- $\mathrm{O}_{2}$ threshold for apple fruit. Once identified, the $\mathrm{O}_{2}$ level in the storage is set at $0.1 \%$ to $0.2 \%$ above the threshold resulting in maximal quality retention, including higher maintenance of cortical firmness and marked suppression of superficial scald. Significant accumulation of fermentative by-products has not been detected in the cultivars tested to date.

This nondestructive and dynamic technology allows rapid, real-time measurements of the condition of stored apple fruit in low- $\mathrm{O}_{2}$ environments without the inconvenience of breaking the room's atmosphere. Our results indicate that HarvestWatch facilitates what may be the highest level of fruit quality retention possible in several apple cultivars during long-term storage without the application of scaldcontrolling or anti-ethylene chemicals before storage.

\section{Literature cited}

Changwen, L. and P.M.A. Tiovonen. 2000. Effect of 1 and $100 \mathrm{kPa} \mathrm{O}$ atmospheric pretreatments of whole 'Spartan' apples on subsequent quality and shelf life of slices stored in modified atmosphere packages. Postharvest Biol. Technol. 18:99-107.

DeEll, J.R. and R.K. Prange. 1994. Recom- 
mended storage conditions for Nova Scotia apples. Storage notes for the apple industry. 2(5):2. Nova Scotia Fruit Growers' Assn., Kentville, Nova Scotia, Canada.

DeEll, J.R., R.K. Prange, and D.P. Murr. 1995. Chlorophyll fluorescence as a potential indicator of controlled-atmosphere disorders in 'Marshall McIntosh' apples. HortScience 30:1084-1085.

DeEll, J.R., R.K. Prange, and D.P. Murr. 1996. Chlorophyll fluorescence of Delicious apples at harvest as a potential predictor of superficial scald development during storage. Postharvest Biol. Technol. 9:1-6.

DeEll, J.R., O. van Kooten, R.K. Prange, and D.P. Murr. 1999. Applications of chlorophyll fluorescence techniques in postharvest physiology. Hort. Rev. 23: 69-107.

DeLong, J.M., R.K. Prange, P.A. Harrison, and K.B. McRae. 2000. Comparison of a new apple firmness penetrometer with three standard instruments. Postharv. Biol. Technol. 19:201-209.

Gunes, G., C.B. Watkins, and J.H. Hotchkiss. 2001. Physiological responses of fresh-cut apple slices under high $\mathrm{CO}_{2}$ and low $\mathrm{O}_{2}$ partial pressures. Postharvest Biol. Technol. 22:197-204.
Lau, O.L., C.L. Barden, S.M. Blankenship, P.M. Chen, E.A. Currry, J.R. DeEll, L. Lehman-Salada, E.J. Mitcham, R.K. Prange, and C.B. Watkins. 1998. A North American cooperative survey of 'Starkrimson Delicious' apple responses to $0.7 \% \mathrm{O}_{2}$ storage on superficial scald and other disorders. Postharvest Biol. Technol. 13:19-26.

Little, C.R., J.D. Faragher, and H.J. Taylor. 1982. Effects of initial oxygen stress treatments in low oxygen modified atmosphere storage of 'Granny Smith' apple. J. Amer. Soc. Hort. Sci. 107:320-323.

Prange, R.K., J.M. DeLong, J.C. Leyte, and P.A. Harrison. 2002. Oxygen concentration affects chlorophyll fluorescence in chlorophyll-containing fruit. Postharvest Biol. Technol. 24:201-205.

Prange, R.K., J.M. DeLong, and P.A. Harrison. 2003. Oxygen concentration affects chlorophyll fluorescence in chlorophyllcontaining fruits and vegetables. J. Amer. Soc. Hort. Sci. 128:603-607.

SAS Institute. 1994. SAS/STAT user's guide. Vol 2. GLM-VARCOMP. version 6. $4^{\text {th }}$ ed. SAS Institute, Inc., Cary, N.C.

Song, J., L. Fan, C.F. Forney, and M.A. Jordan. 2001. Using volatile emissions and chlorophyll fluorescence as indicators of heat injury in apples. J. Amer. Soc. Hort. Sci. 126:771-777. 